\title{
Adolescent psychiatry-from the viewpoint of a child and adolescent psychiatrist
}

\author{
Robert Waltereit $^{1} \cdot$ Anne Uhlmann $^{1} \cdot$ Veit Roessner $^{1}$
}

Published online: 29 September 2018

c) Springer-Verlag GmbH Germany, part of Springer Nature 2018

Adolescence is the phase of life that marks the transition from childhood to adulthood. Adolescence and its transition points, the end of childhood and the beginning of adulthood, are not clearly defined by biological maturation, but rather by psychological, sociological, legal and cultural perspectives [1].

With respect to mental disorders, childhood is characterized by the onset of specific developmental conditions such as ADHD and autism spectrum disorders. On the other hand, first symptoms of the majority of mental disorders contributing to the disease burden in adults tend to appear during adolescence [2, 3]. Hence, adolescence is a focal point of psychiatric research and treatment. Consequently and irrespectively of the semantic circumstance that adolescence is part of this journal's name, reports both in the current issue $[4,5]$ and numerous ones in previous issues [6-11] deal with adolescent psychiatry.

Both child and adolescent psychiatry as well as general psychiatry claim adolescence and its mental disorders as part of their profession. This raises several questions, not only of the specific competencies of these two disciplines, but also pertaining to the cooperation between them and the transition of patients. In some countries, child and adolescent psychiatry is a specialization after training in general psychiatry, while in others, child and adolescent psychiatry is similar to pediatric medicine an independent field.

General psychiatry has shown an increased interest in adolescence during the past years. Several reasons seem to have triggered this development. The traditional view of general psychiatry is to treat a significant proportion of young adults. However, the typical patient treated at a general psychiatric department nowadays is usually older-this goes in line with the development of geriatric psychiatry.

Veit Roessner

veit.roessner@uniklinikum-dresden.de

1 Department of Child and Adolescent Psychiatry, TU Dresden, Fetscherstrasse 74, 01307 Dresden, Germany
Many mental disorders take a chronic course over extended time periods, but their onset often occurs during adolescence. Therefore, early treatment is seen as an opportunity to prevent such chronic developments. Research of the last decades has revealed that the onset of the major mental disorders such as schizophrenia, unipolar depression, bipolar disorder, personality disorders and substance use disorders, does not only date back to adolescence, but often even to the period before the 18th birthday, which represents the formal divide between child and adolescent psychiatry and general psychiatry. Early detection of at-risk states for psychoses and early treatment with the hope of disease prevention has been an important concern of the last decades and is associated with prominent protagonists [12]. Another development that derives from the growing interest of general psychiatry in adolescence is the appearance of adolescent treatment units. These are often established as centers for early recognition of mental disorders, mostly on behalf of general psychiatry than of child and adolescent psychiatry.

At the University Hospital Carl Gustav Carus, adolescence was defined for health care management purposes as the period from 14.0 to 24.9 years. An analysis of all inhouse patients in this age range treated for a mental disorder in 2017 revealed that about 60\% were treated at our Department of Child and Adolescent Psychiatry. We assume that these data may also be representative for other hospitals in Germany. In 2016, we conducted an unpublished survey on the treatment situation of patients under the age of 18 years at early recognition centers. We asked all departments of child and adolescent psychiatry at university hospitals in Germany with a local early recognition center how underage patients suspected of being at-risk for psychosis [13] would be handled at this early recognition center. Out of twelve contacted departments, nine responded to our survey. Four of these nine departments had a cooperation with their local early recognition center, which in eleven out of twelve cases was run only by general psychiatry. In the case of an existing cooperation with the early recognition center, in three out of 
the four departments the general psychiatrist was involved in diagnosing patients under the age of 18 . In one department, only the general psychiatrist made the diagnosis. However, all nine university departments for child and adolescent psychiatry stated that they would consider making the diagnosis of a psychosis or at-risk state part of their overall diagnostic portfolio, irrespective of referring the patient to an early recognition center.

Child and adolescent psychiatry provides the diagnostic, and more importantly, the treatment tools to take care of the specific needs of a very young group of psychiatric patients. Unlike in adulthood, during childhood and adolescence, the neurobiological, psychological and social foundations of development change rapidly and require specific expertise in case of abnormalities. To serve these needs, child and adolescent psychiatry does not only provide conventional psychiatric skills and instruments, but also provides the ability to consider, diagnose and treat patients in social systems such as families and peer groups. It generates-due to the nature of its patient group-the opportunity to work in multidisciplinary teams including professionals from the youth welfare system, schools and other educational institutions. Work in child and adolescent psychiatry does not only require expertise in psychiatry and medicine, but also in educational science and a substantial knowledge of normal and abnormal developments of the nervous system and behavior. Hence, in child and adolescent psychiatry, the physician is collaborating in mutual support with a large multidisciplinary team of therapists, co-therapists, social workers, nurses and educators.

Healthy adolescents reach out for adult life and experiences. However, in adolescent psychiatric patients of 18 years and older, due to a reciprocal dependency of mental disorders and delayed psychosocial developments, the substantial needs are more comparable with those of adolescents aged 14-17 years than with healthy peers [14-16]. Thus, these patients require similar treatment options. From our point of view, they need a therapeutic setting that is at least an extension of the standards in child and adolescent psychiatry. These standards include, besides a rigid diagnostic and therapeutic expertise in psychiatry, intensive multidisciplinary care, work with the family, a therapeutic environment with both peers and the presence of family-like caregivers, as well as support and opportunities in school, education, sports, and leisure programs. There should be adherence of the staff to such a setting, robust clinical supervision and regular professional development.

With regard to patients under the age of 18 , early detection and differential diagnosis of developing mental disorders is the intrinsic approach of every child and adolescent psychiatrist. In their mental states, adolescents are, less than children but still more than adults, dependent on their social environment, notably on interactions with caregivers and peers. In children and adolescents, a thorough clinical examination of the patient and their relatives accompanied by a systemic and multidisciplinary behavioral assessment in an inpatient setting is superior to diagnostics with interviews and rating scales like in an outpatient setting. The additional participation of such adolescents in an early recognition center could complement our child and adolescent psychiatric care, notably when they are run by both disciplines. Accordingly, we may need to come up with "transition boards" including professionals of both disciplines to allow discussions of relevant cases and longer-term outcomes to be reported back to child and adolescent psychiatry, and finally to allow mutual preparation of the patient for transition into general psychiatry.

In summary, we think that cooperation is the key to promoting both best psychiatric practice for adolescents and a successful transition from child and adolescent psychiatry to general psychiatry. We suggest that child and adolescent psychiatry should not "hide its light under the bushel", but be established more broadly and confidently according to apparent needs of this patient group.

\section{References}

1. Remschmidt H (2013) Mental health and psychological illness in adolescence. Dtsch Arztebl Int 110:423-424. https://doi. org/10.3238/arztebl.2013.0423

2. Merikangas KR, He J-P, Burstein M et al (2010) Lifetime prevalence of mental disorders in US adolescents: results from the National Comorbidity Survey Replication-Adolescent Supplement (NCS-A). J Am Acad Child Adolesc Psychiatry 49:980-989. https ://doi.org/10.1016/j.jaac.2010.05.017

3. Steel Z, Marnane C, Iranpour C et al (2014) The global prevalence of common mental disorders: a systematic review and meta-analysis 1980-2013. Int J Epidemiol 43:476-493. https:// doi.org/10.1093/ije/dyu038

4. Ranøyen I, Lydersen S, Larose TL et al (2018) Developmental course of anxiety and depression from adolescence to young adulthood in a prospective Norwegian clinical cohort. Eur Child Adolesc Psychiatry. https://doi.org/10.1007/s00787-018-1139-7

5. Herring MP, Monroe DC, Kline CE et al (2018) Sleep quality moderates the association between physical activity frequency and feelings of energy and fatigue in adolescents. Eur Child Adolesc Psychiatry. https://doi.org/10.1007/s00787-018-1134-z

6. Koenig J, Brunner R, Fischer-Waldschmidt G et al (2017) Prospective risk for suicidal thoughts and behaviour in adolescents with onset, maintenance or cessation of direct self-injurious behaviour. Eur Child Adolesc Psychiatry 26:345-354. https:// doi.org/10.1007/s00787-016-0896-4

7. Benjet C, Borges G, Mendez E et al (2016) Eight-year incidence of psychiatric disorders and service use from adolescence to early adulthood: longitudinal follow-up of the Mexican adolescent mental health survey. Eur Child Adolesc Psychiatry 25:163-173. https ://doi.org/10.1007/s00787-015-0721-5

8. Seymour KE, Jones RN, Cushman GK et al (2016) Emotional face recognition in adolescent suicide attempters and adolescents 
engaging in non-suicidal self-injury. Eur Child Adolesc Psychiatry 25:247-259. https://doi.org/10.1007/s00787-015-0733-1

9. Sole-Padulles C, Castro-Fornieles J, de la Serna E et al (2017) Intrinsic functional connectivity of fronto-temporal networks in adolescents with early psychosis. Eur Child Adolesc Psychiatry 26:669-679. https://doi.org/10.1007/s00787-016-0931-5

10. Takagaki K, Okamoto Y, Jinnin R et al (2016) Behavioral activation for late adolescents with subthreshold depression: a randomized controlled trial. Eur Child Adolesc Psychiatry 25:11711182. https://doi.org/10.1007/s00787-016-0842-5

11. Keller LK, Grunewald B, Vetter C et al (2017) Not later, but longer: sleep, chronotype and light exposure in adolescents with remitted depression compared to healthy controls. Eur Child Adolesc Psychiatry 26:1233-1244. https://doi.org/10.1007/s0078 7-017-0977-z

12. McGorry PD, Nelson B, Amminger GP et al (2009) Intervention in individuals at ultra-high risk for psychosis: a review and future directions. J Clin Psychiatry 70:1206-1212. https://doi. org/10.4088/JCP.08r04472
13. Yung AR, McGorry PD, McFarlane CA et al (1996) Monitoring and care of young people at incipient risk of psychosis. Schizophr Bull 22:283-303

14. McLaughlin KA, Greif Green J, Gruber MJ et al (2012) Childhood adversities and first onset of psychiatric disorders in a national sample of US adolescents. Arch Gen Psychiatry 69:1151-1160. https://doi.org/10.1001/archgenpsychiatry.2011.2277

15. Wille N, Bettge S, Ravens-Sieberer U (2008) Risk and protective factors for children's and adolescents' mental health: results of the BELLA study. Eur Child Adolesc Psychiatry 17(Suppl 1):133-147. https://doi.org/10.1007/s00787-008-1015-y

16. Clark C, Caldwell T, Power C, Stansfeld SA (2010) Does the influence of childhood adversity on psychopathology persist across the lifecourse? A 45-year prospective epidemiologic study. Ann Epidemiol 20:385-394. https://doi.org/10.1016/j.annep idem.2010.02.008 